\title{
Endoscopic ultrasound-guided management of malignant afferent loop syndrome after gastric bypass: from diagnosis to therapy
}

Afferent loop syndrome (ALS) is a known complication of surgical gastrectomy [1], caused by benign or malignant obstruction of the afferent limb, which induces digestive intolerance and reflux cholangitis. With the explosion of bariatric surgery, a new patient population with altered anatomy has emerged [2], presenting new endoscopic challenges. Therapeutic possibilities using endoscopic ultrasound (EUS) are constantly increasing thanks to new devices $[3,4]$. We present an original case of a patient with ALS due to pancreatic adenocarcinoma that occurred years after a gastric bypass.

The 57-year-old woman presented with abdominal pain, nausea, fever, and jaundice. Her previous history included a sleeve gastrectomy in 2007, which was converted to a gastric bypass in 2008. Laboratory results revealed an inflammatory syndrome with a picture of cholestatic jaundice. The diagnosis of ALS was confirmed by a computed tomography (CT) scan that showed a non-resectable pancreatic tumor invading the 4th part of the duodenum, with digestive and biliary tree dilatation ( $\vee$ Fig. $\mathbf{1}$ a). Antibiotic therapy was started with ciprofloxacin and metronidazole.

An EUS was performed for diagnostic and therapeutic purposes ( Video 1). First, the examination showed a 40-mm hypoechogenic, heterogeneous lesion of the pancreatic body with contact and invasion $\left(>180^{\circ}\right)$ of the splenic artery and

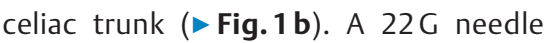
was used to obtain a specimen for histological diagnosis (> Fig. 2). An EUS-guided gastro-gastrostomy was the performed, using a lumen-apposing metal stent (LAMS) with an electrocautery-enhanced delivery system (Hot Axios; Boston Scientific, USA) placed between the dilated gastric pouch ( $\triangleright$ Fig. $\mathbf{2} \mathbf{b}$ ) and the stomach after direct puncture ( $\triangleright$ Fig.3). There were no perioperative complications and a CT scan performed 1 week
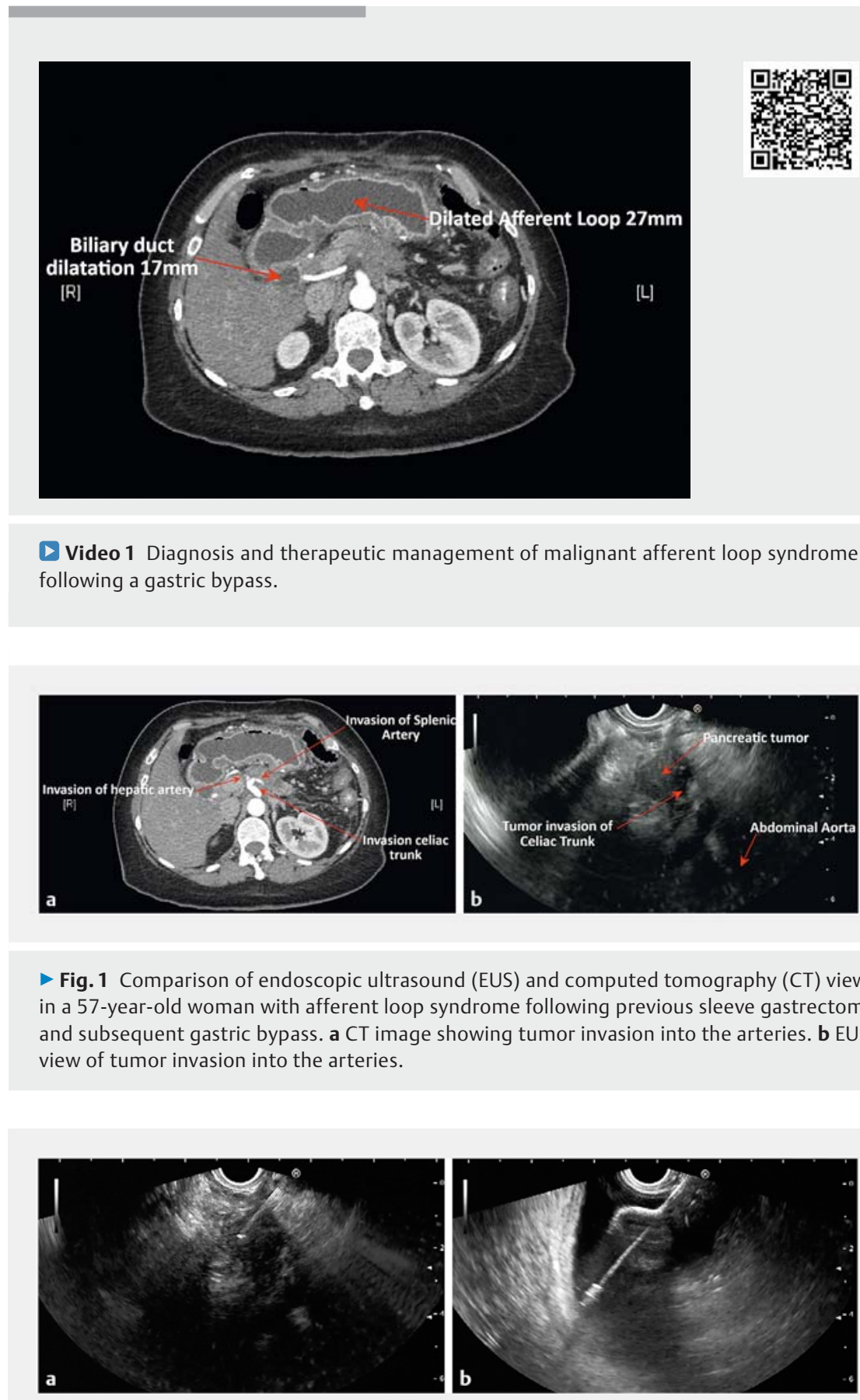

- Fig. 2 Endoscopic ultrasound (EUS) images showing: a EUS-guided puncture with a fine needle biopsy needle; $\mathbf{b}$ creation of a gastrojejunostomy using a lumen-apposing metal stent with the distal flange deployed into the duodenum under EUS control. 


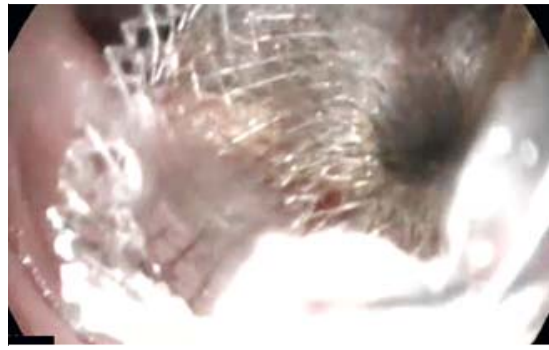

- Fig. 3 Endoscopic image showing the proximal flange of the lumen-apposing metal stent deployed in the lumen under endoscopic control.

later confirmed a decrease in the dilatation of the biliary duct and afferent limb, with good positioning of the stent. Histologic results confirmed an adenocarcinoma of the pancreas. After the procedure, the patient improved clinically and biologically, so allowing chemotherapy to be started.

This case illustrates the significant contribution of therapeutic EUS in the management of ALS after gastric bypass by creating a gastro-gastric anastomosis using a LAMS.

Endoscopy_UCTN_Code_TTT_1AS_2AG
Competing interests

None

The authors

\section{Laurent Monino ${ }^{1,2}$, Marc Barthet ${ }^{2}$, Jean}

Michel Gonzalez ${ }^{2}$

1 Department of Hepatogastroenterology, Université Catholique de Louvain, Cliniques Universitaires Saint-Luc, Brussels, Belgium

2 Department of Hepatogastroenterology, Assistance Publique des Hôpitaux de Marseille, Aix-Marseille Université, Hôpital Nord, Marseille, France

\section{Corresponding author}

\section{Laurent Monino, MD}

Department of Hepatogastroenterology, AP-HM, Aix-Marseille Université, Hôpital Nord, Chemin des Bourrely, 13015 Marseille, France

Fax: +33-4-91968737

laurent.monino@uclouvain.be

\section{References}

[1] Davis JL, Ripley RT. Postgastrectomy Syndromes and Nutritional Considerations Following Gastric Surgery. Surg Clin North Am 2017; 97: 277-293

[2] Angrisani L, Santonicola A, lovino P et al. Bariatric Surgery Worldwide 2013. Obes Surg 2015; 25: $1822-1832$
[3] Tyberg A, Nieto ], Salgado S et al. Endoscopic ultrasound (EUS)-directed transgastric endoscopic retrograde cholangiopancreatography or EUS: mid-term analysis of an emerging procedure. Clin Endosc 2016; 50 : 185-190

[4] Rimbaş M, Larghi A, Costamagna G. Endoscopic ultrasound-guided gastroenterostomy: Are we ready for prime time? Endosc Ultrasound 2017; 6: 235

\section{Bibliography}

DOI https://doi.org/10.1055/a-0948-5033

Published online: 1.7.2019

Endoscopy 2020; 52: E84-E85

(c) Georg Thieme Verlag KG

Stuttgart · New York

ISSN 0013-726X

\section{ENDOSCOPY E-VIDEOS}

https://eref.thieme.de/e-videos

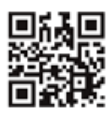
Endoscopy E-Videos is a free access online section, reporting on interesting cases and new

techniques in gastroenterological endoscopy. All papers include a high quality video and all contributions are freely accessible online.

This section has its own submission website at https://mc.manuscriptcentral.com/e-videos 